\title{
Structural, infrared reflectivity spectra and microwave dielectric properties of the $\mathrm{Li}_{7} \mathrm{Ti}_{3} \mathrm{O}_{9} \mathrm{~F}$ ceramic
}

Zhiwei Zhang, Liang Fanga, Huaicheng Xianga, Minyu Xua, Ying Tanga, Heli Jantunen, Chunchun Li

\section{Abstract}

A cubic rock salt structured ceramic, $\mathrm{Li}_{7} \mathrm{Ti}_{3} \mathrm{O}_{9} \mathrm{~F}$, was fabricated via the conventional solid-state reaction route. The synthesis conditions, sintering characteristics, and microwave dielectric properties of $\mathrm{Li}_{7} \mathrm{Ti}_{3} \mathrm{O}_{9} \mathrm{~F}$ ceramics were investigated by X-ray diffraction (XRD), thermal dilatometer, Scanning Electron Microscopy (SEM) accompanied with EDS mapping, and microwave resonant measurements. Rietveld refinement, selected area electron diffraction (SAED) pattern and high-resolution transmission electron microscopy (HRTEM) confirmed that $\mathrm{Li}_{7} \mathrm{Ti}_{3} \mathrm{O}_{9} \mathrm{~F}$ adopts a cubic rock-salt structure. The ceramic sintered at $950{ }^{\circ} \mathrm{C}$ presented the optimal microwave properties of $\varepsilon_{\mathrm{r}}=22.5, \mathrm{Q} \times \mathrm{f}=88,200 \mathrm{GHz}$, and $\tau_{\mathrm{f}}=-24.2 \mathrm{ppm} /{ }^{\circ} \mathrm{C}$. Moreover, good chemical compatibility with $\mathrm{Ag}$ was verified through cofiring at $950{ }^{\circ} \mathrm{C}$ for $2 \mathrm{~h}$. These results confirm a large potential for $\mathrm{Li}_{7} \mathrm{Ti}_{3} \mathrm{O}_{9} \mathrm{~F}$ ceramic to be utilized as substrates in the low temperature cofired ceramic (LTCC) technology. This work provides the possibility to exploit low-temperature-firing ceramics through solid solution between oxides and fluorides.

\section{Introduction}

Recent progress in the Internet of Things (IOT), microwave telecommunications, Tactile Internet (5th generation wireless systems), and satellite broadcasting has led to an increasing demand for low-loss dielectric materials [1,2]. For practical applications, the critical properties required are an appropriate dielectric constant $\left(\varepsilon_{r}\right)$, a high quality factor $(\mathrm{Q} \times \mathrm{f})$, a near-zero temperature coefficient of resonant frequency $\left(\tau_{f}\right)$, and a coefficient of thermal expansion (CTE) matched with other materials in integrations, etc. [3-5]. The toxicity and cost-effectiveness of the materials should also be considered [6]. Moreover, in order to meet the requirements of the low-temperature cofired ceramics (LTCC) technology, the ceramics should also be sintered below $960^{\circ} \mathrm{C}$ to allow them to be cofired with a low-cost Ag electrode. Of primary significance is the low sintering temperature of LTCC technology which decreases energy consumption resulting in cost reductions, and less impact on the environment $[7,8]$.

Rock salt structured $\mathrm{Li}_{2} \mathrm{TiO}_{3}$ has recently been reported to possess good microwave dielectric properties $\left(\varepsilon_{\mathrm{r}}=22.0, \mathrm{Q} \times \mathrm{f}=63,500 \mathrm{GHz}\right.$, and $\left.\tau_{\mathrm{f}}=20.3 \mathrm{ppm} /{ }^{\circ} \mathrm{C}\right)$ [9]. However, the porous microstructure caused by lithium evaporation was reported to be a primary challenge for its practical applications. In addition, $\mathrm{Li}_{2} \mathrm{TiO}_{3}$ undergoes an order-disorder phase transition at $1215{ }^{\circ} \mathrm{C}$, which makes it difficult to obtain a pure $\mathrm{Li}_{2} \mathrm{TiO}_{3}$ phase with high densification [10-12]. Attempts have been made to improve the low densification of $\mathrm{Li}_{2} \mathrm{TiO}_{3}$ through non-stoichiometry modulation and solid solution modifications, such as $\mathrm{Li}_{2+\times} \mathrm{TiO}_{3}$ [12], and $\mathrm{Li}_{2 \times} \mathrm{Mg}_{1-}$ ${ }_{x} \mathrm{Ti}_{x} \mathrm{O}_{1+2 x}$ [13]. Particularly, in the latter system, a number of low-loss rock salt structured dielectric materials have been designed in the $\mathrm{Li}_{2} \mathrm{TiO}_{3}-\mathrm{MgO}$ solid solution [15-20]. In spite of a the dramatically improved microstructure and enhanced quality factors with respect to the end-member $\mathrm{Li}_{2} \mathrm{TiO}_{3}$, the sintering temperatures were unfortunately raised which limits their actual applications in the LTCC technology. 
$\mathrm{LiF}$ has a face-centered cubic rock salt structure, which is similar to that of $\mathrm{Li}_{2} \mathrm{TiO}_{3}$ being a superstructure with an edge-sharing cation oxygen octahedral structure [22-24]. Therefore, partial or complete solid solution between $\mathrm{Li}_{2} \mathrm{TiO}_{3}$ and $\mathrm{LiF}$ is expected. Moreover, $\mathrm{LiF}$ is commonly used as a sintering aid to improve the sintering behavior of ceramics due to its low melting point $\left(848{ }^{\circ} \mathrm{C}\right)[25,26]$. Herein, a glassfree lowtemperature fired microwave dielectric ceramic $\mathrm{Li}_{7} \mathrm{Ti}_{3} \mathrm{O}_{9} \mathrm{~F}$ was designed. Its crystal structure, microstructure, and microwave dielectric properties were studied in detail. The chemical compatibility of $\mathrm{Li}_{7} \mathrm{Ti}_{3} \mathrm{O}_{9} \mathrm{~F}$ ceramics with $\mathrm{Ag}$ was also investigated.

\section{Experimental procedure}

$\mathrm{Li}_{7} \mathrm{Ti}_{3} \mathrm{O}_{9} \mathrm{~F}$ samples were prepared via the solid-state reaction using high-purity $\mathrm{Li}_{2} \mathrm{CO} 1 \frac{1}{2}$ (99.99\%, Guo-Yao Co. Ltd., Shanghai, China), $\mathrm{TiO}_{2}$ (99.99\%, Guo-Yao Co. Ltd., Shanghai, China), and LiF (99.99\%, Xilong Chemicals, Guangdong, China) powders as starter materials. The raw powders were weighed according to the stoichiometry and ball-milled with $\mathrm{ZrO}_{2}$ balls and alcohol as milling media in a polyethylene jar for $6 \mathrm{~h}$. After drying at $120^{\circ} \mathrm{C}$, the mixtures were calcined at $800^{\circ} \mathrm{C}$ for $2 \mathrm{~h}$, and then re-milled for $6 \mathrm{~h}$. The compound was dried and granulated with $5 \mathrm{wt} \%$ PVA as binder, and then pressed into cylinders under a pressure of 150 $\mathrm{MPa}$. The cylinders were heated at $550^{\circ} \mathrm{C}$ for $2 \mathrm{~h}$ to burn out the PVA and then subsequently sintered at $875-$ $975^{\circ} \mathrm{C}$ for $2 \mathrm{~h}$. In order to minimize the volatilization of lithium during sintering, the samples were covered with sacrificial powders with the same composition. To investigate the chemical compatibility of $\mathrm{Li}_{7} \mathrm{Ti}_{3} \mathrm{O}_{9} \mathrm{~F}$ with Ag electrodes, the compounds were mixed with $20 \mathrm{wt} \%$ silver powders and cofired at $950{ }^{\circ} \mathrm{C}$ for $2 \mathrm{~h}$.

The phase formation of $\mathrm{Li}_{7} \mathrm{Ti}_{3} \mathrm{O}_{9} \mathrm{~F}$ was studied by XRD (Panalytical X'pert Pro diffractometer with $\mathrm{Cu} \mathrm{K} \alpha$ radiation). Rietveld refinement was performed on the XRD data using Topas-Academic software. The bulk densities of samples were determined using the Archimedes method. The microstructure and energydispersive X-ray spectroscopy (EDS) analyses were performed using a Hitachi S4800 scanning electron microscope (SEM). Room-temperature Raman spectra were recorded using a Thermo Fisher Scientific DXR Raman spectrometer. The highresolution transmission electron microscope (HRTEM) images and the selected-area electron diffraction (SAED) patterns were collected by a JEOL JEM-2100F TEM. XPS measurements were performed with an ESCALAB 250Xi X-ray photoelectron spectrometer with monochromatized Al Ka radiation. Microwave dielectric properties were measured by an Agilent N5230A network analyzer and a Delta 9039 oven. The $\tau_{f}$ value was measured in the temperature range of $25-85^{\circ} \mathrm{C}$. The linear coefficient of thermal expansion $(\alpha \mathrm{L})$ of the ceramics was measured by a NETZSCH DIL402C thermal dilatometer.

\section{Results and discussion}

XRD patterns of the $\mathrm{Li}_{7} \mathrm{Ti}_{3} \mathrm{O}_{9} \mathrm{~F}$ ceramics fired at various temperatures are shown in Fig. 1 (a). A cubic rock-salt structure was identified based on PDF\# 03-1024 of $\mathrm{Li}_{2} \mathrm{TiO}_{3}\left(\alpha-\mathrm{Li}_{2} \mathrm{TiO}_{3}(\mathrm{SS}), \mathrm{Fm}-3 \mathrm{~m}\right.$ ) and no secondary phase was detected. Fig. 1 (b) shows the Rietveld refinement plots of $\mathrm{Li}_{7} \mathrm{Ti}_{3} \mathrm{O}_{9} \mathrm{~F}$ ceramics sintered at $950{ }^{\circ} \mathrm{C}$. The cell parameters were refined as $a=b=c=4.1340(1) \AA$, and $V_{m}=70.6541(8) \AA^{3}$. The schematic crystal structure is shown in the inset of Fig. 1 (b), which can be described as O/F anions randomly stacking in a cubic close packing with $\mathrm{Li} / \mathrm{Ti}$ cations occupying the octahedron sites. To further confirm the structure of the $\mathrm{Li}_{7} \mathrm{Ti}_{3} \mathrm{O}_{9} \mathrm{~F}$ sample, a selected area electron diffraction (SAED) pattern and high-resolution transmission electron microscopy (HRTEM) were performed. Fig. 1 (c) and (d) present the SAED patterns and HRTEM images of $\mathrm{Li}_{7} \mathrm{Ti}_{3} \mathrm{O}_{9} \mathrm{~F}$ ceramic recorded along the [001] zone axis. The SAED pattern and the lattice fringes of the sample display interplanar spacing in the particle and were well matched with the cubic rack model (space group:Fm$3 \mathrm{~m}$, No.225). In conclusion, these results indicated that $\mathrm{Li}_{7} \mathrm{Ti}_{3} \mathrm{O}_{9} \mathrm{~F}$ is a cubic structure, which is consistent with the XRD refinement results. 
Fig. 2 shows the naturally fresh surface morphologies of $\mathrm{Li}_{7} \mathrm{Ti}_{3} \mathrm{O}_{9} \mathrm{~F}$ ceramics sintered at various temperatures and the element mapping of the constituents on the $950{ }^{\circ} \mathrm{C}$ sintered sample. The grain size distributions and the average grain size of $\mathrm{Li}_{7} \mathrm{Ti}_{3} \mathrm{O}_{9} \mathrm{~F}$ are given in the inset of Fig. 2 (a)-(e). At $900^{\circ} \mathrm{C}$, the grain size was relatively small between 6 and $12 \mu \mathrm{m}$, whereas the sample sintered at $950^{\circ} \mathrm{C}$ had larger grains, about $14-20 \mu \mathrm{m}$. The average grain size increased from $7.78 \mu \mathrm{m}$ to $19.98 \mu \mathrm{m}$ when the temperature increased from $875^{\circ} \mathrm{C}$ to 975 ${ }^{\circ} \mathrm{C}$. A dense and homogeneous microstructure with an average grain size of $\sim 16 \mu \mathrm{m}$ was obtained in the sample sintered at $950^{\circ} \mathrm{C} / 2 \mathrm{~h}$, (Fig. 2 (d)). However, partial melting together with abnormally large grains $(\sim 30 \mu \mathrm{m})$ and a small amount of porosity was clearly distinguished in the $\mathrm{Li}_{7} \mathrm{Ti}_{3} \mathrm{O}_{9} \mathrm{~F}$ ceramic sintered at 975 ${ }^{\circ} \mathrm{C}$. To analyze the element distributions, element mapping of the constituents on the $950{ }^{\circ} \mathrm{C}$ sintered sample is displayed in Fig. 2 (g)-(i). It is obvious that all elements ( $F, O$, and Ti) were distributed homogeneously, and no element precipitation was observed at the grain boundary, further suggesting that LiF entered into the crystal lattice of $\mathrm{Li}_{2} \mathrm{TiO}_{3}$.

Fig. 3 shows the variations in bulk density and microwave dielectric properties of $\mathrm{Li}_{7} \mathrm{Ti}_{3} \mathrm{O}_{9} \mathrm{~F}$ ceramic with sintering temperature in the range $875-975^{\circ} \mathrm{C}$. As the sintering temperature increased, the bulk density gradually increased to a maximum value of $\sim 3.15 \mathrm{~g} / \mathrm{cm}^{3}$ with a relative density of $94.3 \%$ at $950{ }^{\circ} \mathrm{C}$. It is wellknown that many factors affect dielectric properties, such as lattice vibration, the density, ionic polarizability, order-disorder, grain boundaries, and secondary phase, etc. [27-32]. In this work, the dielectric constant steadily increased on increasing the sintering temperature from 875 to $950{ }^{\circ} \mathrm{C}$, as a result of the increasing density. Similarly, the quality factor increased with increasing sintering temperature, reaching a maximum value of $88,200 \mathrm{GHz}$ at $950{ }^{\circ} \mathrm{C}$. In contrast, the temperature coefficient of resonant frequency of $\mathrm{Li}_{7} \mathrm{Ti}_{3} \mathrm{O}_{9} \mathrm{~F}$ ceramics remained temperature independent, fluctuating at around $-24 \mathrm{ppm} /{ }^{\circ} \mathrm{C}$ (Fig. 3 (d)). The tf value is related to the temperature coefficient of the relative permittivity $\left(\tau_{\varepsilon}\right)$, and the linear thermal expansion coefficient, $\alpha_{L}$, as follows [33]:

$$
\tau_{f}=-\left(\frac{\tau_{\varepsilon}}{2}+\alpha_{L}\right)
$$

From the CTE curve of $\mathrm{Li}_{7} \mathrm{Ti}_{3} \mathrm{O}_{9} \mathrm{~F}$ ceramic sintered at $950{ }^{\circ} \mathrm{C}$ shown in Fig. $4(\mathrm{a})$, the average linear thermal expansion coefficient $\alpha_{\llcorner}$was calculated to be $11.20 \mathrm{ppm} /{ }^{\circ} \mathrm{C}$.

Fig. 4 (b) shows the temperature dependence of dielectric constant $\left(\varepsilon_{r}\right)$ and loss tangent $(\tan \delta)$ at various frequencies. $\varepsilon_{\mathrm{r}}$ and $\tan \delta$ showed good temperature stability between room temperature and $180^{\circ} \mathrm{C}$. The profile measured at $1 \mathrm{MHz}$ from 25 to $85{ }^{\circ} \mathrm{C}$ is shown in the inset of Fig. 4 (b), yielding a $\tau_{\varepsilon}$ value of 34.4 $\mathrm{ppm} /{ }^{\circ} \mathrm{C}$, resulting in a $\tau_{f}$ value of $-28.4 \mathrm{ppm} /{ }^{\circ} \mathrm{C}$ according to Eq. (1). This calculated value is a little higher than the value measured at microwave frequency $\left(-24.2 \mathrm{ppm} /{ }^{\circ} \mathrm{C}\right)$, which might be due to the different measurement frequency. Besides, it is worth mentioning that a frequency dispersion related to the thermally activated polarizability mechanisms was observed as the measurement temperature exceeded to $200^{\circ} \mathrm{C}$. The frequency dispersion responded instantly at low frequency but it lagged at high frequency [34]. As a result, a higher relative permittivity $\left(\varepsilon_{\mathrm{r}} \sim 39\right)$ at $1 \mathrm{MHz}$ was measured compared to that at microwave frequency $\left(\varepsilon_{\mathrm{r}} \sim 22.5\right)$.

To study this high-frequency dielectric anomaly, X-ray photoelectron spectroscopy (XPS) was conducted on the $\mathrm{Li}_{7} \mathrm{Ti}_{3} \mathrm{O}_{9} \mathrm{~F}$ sample sintered at $950^{\circ} \mathrm{C}$ (Fig. $5(\mathrm{a}, \mathrm{b})$ ). To clarify, the $\mathrm{C}$ element detected was introduced during the measurement process. The Ti- $2 p$ regions in the sample were fitted well into the Gaussian sub peaks. Three dominant peaks ( $457.8 \mathrm{eV}, 458.3 \mathrm{eV}$, and $464 \mathrm{eV}$ ) were clearly distinguished. According to the previous work, the $458.3 \mathrm{eV}$ and $464 \mathrm{eV}$ correspond to $\mathrm{Ti}^{4+}$ while the $457.8 \mathrm{eV}$ is related to the $\mathrm{Ti}^{3+} 2 \mathrm{p}$ peak $[35,36]$. The ratio of $\left(\mathrm{Ti}^{3+}\right) /(\mathrm{Ti})_{\text {total }}$ was estimated to be approximately $2 \%$ based on the method proposed by Borchert et al. [37]. It is well known that valence variation in titanium is ubiquitous, especially in oxides being sintered at elevated temperatures, and it is believed to be related to the released electrons due to the emergence of an oxygen vacancy [38-40]. The chemical defect equation can be expressed as follows: 


$$
\begin{aligned}
& O_{O}^{x} \Leftrightarrow V_{O}^{x}+\frac{1}{2} O_{2} \\
& V_{O} \Leftrightarrow V_{O}^{\cdot}+e^{\prime} \\
& V_{O}^{\cdot} \Leftrightarrow V_{O}^{\ddot{\prime}}+e^{\prime} \\
& T i_{T i}^{x}+e^{\prime} \Leftrightarrow T i_{T i}^{\prime}
\end{aligned}
$$

The negatively charged $T i_{T i}^{\prime}$ can bond weakly to the neighboring positively charged $V_{O}^{*}$, resulting in defect dipoles, perhaps in the form of $T i_{T i}^{\prime}-V_{O}^{\prime}-T i_{T i}^{\prime}$. These kinds of dipoles could offer a contribution to the dielectric properties, especially at low frequencies, but cannot follow the high-frequency change because of the large time constant, consequently giving rise to the manifest frequency dependence of the dielectric behaviors. Additionally, because of the weak-coupling energy, the bonding can be broken at a certain temperature, and thus, the unbonded point defects can move freely to some extent, yielding conductivity losses that contributes to the high-temperature rise in dielectric losses.

Fig. 6 shows the Raman spectra of $\mathrm{Li}_{7} \mathrm{Ti}_{3} \mathrm{O}_{9} \mathrm{~F}$ ceramics sintered at $875-975^{\circ} \mathrm{C}$. A profile of a pure $\mathrm{Li}_{2} \mathrm{TiO}_{3}$ sample sintered at $1300{ }^{\circ} \mathrm{C}$ is also shown for comparison. After fitting by the Gaussian-Lorentzian function, seven Raman active modes at $140 \mathrm{~cm}^{-1}, 286 \mathrm{~cm}^{-1}, 348 \mathrm{~cm}^{-1}, 430 \mathrm{~cm}^{-1}, 710 \mathrm{~cm}^{-1}, 804 \mathrm{~cm}^{-1}$, and $834 \mathrm{~cm}^{-1}$ were detected.

Irrespective of their sintering temperatures, all the $\mathrm{Li}_{7} \mathrm{Ti}_{3} \mathrm{O}_{9} \mathrm{~F}$ compositions showed similar profiles indicating structural stability over the temperature range studied. By comparison, the completely different Raman spectra for $\mathrm{Li}_{7} \mathrm{Ti}_{3} \mathrm{O}_{9} \mathrm{~F}$ and $\mathrm{Li}_{2} \mathrm{TiO}_{3}$ indicate their different structure, which further reveals the solid solution between $\mathrm{LiF}$ and $\mathrm{Li}_{2} \mathrm{TiO}_{3}$.

The far infrared reflectivity spectrum is generally used to characterize the eigen dielectric properties of microwave ceramics [41] The measured and fitted IR reflectivity spectra of the $\mathrm{Li}_{7} \mathrm{Ti}_{3} \mathrm{O}_{9} \mathrm{~F}$ ceramic in the range $50-1000 \mathrm{~cm}^{-1}$ are plotted in Fig. 7(a). It can be seen that the infrared spectra can be well fitted by 6 resonant modes, and the related phonon parameters are listed in Table 1 . These spectra were analysed by using the classical harmonic oscillator model based on the standard Lorentzian formula [Eq (6)] and the Fresnel formula [Eq (7)] [42,43].

$$
\begin{aligned}
& \varepsilon^{*}(\omega)=\varepsilon_{\infty}+\sum_{j=1}^{n} \frac{\omega_{p j}^{2}}{\omega_{o j}^{2}-\omega^{2}-j \omega \gamma_{j}} \\
& R(\omega)=\left|\frac{1-\sqrt{\varepsilon^{*}(\omega)}}{1+\sqrt{\varepsilon^{*}(\omega)}}\right|^{2}
\end{aligned}
$$

where $\varepsilon^{*}(\omega)$ is a complex dielectric function, $\varepsilon_{\infty}$ is the dielectric constant caused by the electronic polarization at high frequencies, $\nu_{j}, \omega_{\mathrm{oj}}$ and $\omega_{\mathrm{pj}}$ are the damping factor, the transverse frequency and plasma frequency of the $j$-th Lorentz oscillator, respectively, and $n$ is the number of transverse phonon modes; $R(\omega)$ is the IR reflectivity. Fig. 7 (b) presents the measured and fitted real and imaginary parts of the permittivity. It was observed that the fitted value of $\varepsilon r$ was a little smaller than the measured values in the microwave range. Meanwhile, all the fitted dielectric permittivity and dielectric loss values were nearly equal to the measured ones using the $\mathrm{TE}_{01 \delta}$ method. Therefore, it can be concluded that the polarization of the $\mathrm{Li}_{7} \mathrm{Ti}_{3} \mathrm{O}_{9} \mathrm{~F}$ ceramic in the microwave region was mainly attributed to the absorptions of phonon oscillation in the infrared region.

To investigate the chemical compatibility with the silver electrode, the $\mathrm{Li}_{7} \mathrm{Ti}_{3} \mathrm{O}_{9} \mathrm{~F}$ ceramic powder was chosen to be cofired with 20 wt\% silver ( $\mathrm{Ag}$ ) powders at $950{ }^{\circ} \mathrm{C}$ for $2 \mathrm{~h}$. XRD patterns, a backscattered electron image (BSEM), and EDS analysis of the cofired samples are shown in Fig. 8. $\mathrm{Li}_{7} \mathrm{Ti}_{3} \mathrm{O}_{9} \mathrm{~F}$ and $\mathrm{Ag}$ (PDF: 01-1164) phases were detected, indicating no chemical reaction between them. Additionally, the BSE image, as shown in the inset in Fig. 8, shows two kinds of grains with different sizes and shapes, in which the larger ones may be 
identified as Ag with the help of elemental analysis by energy-dispersive Xray spectroscopy (EDS). These features, in combined with the XRD analysis, confirm no chemical reaction between $\mathrm{Li}_{7} \mathrm{Ti}_{3} \mathrm{O}_{9} \mathrm{~F}$ and silver.

Table 2 compares the reported sintering temperature and microwave dielectric properties of some rock salts being reported. The relative permittivity of $\mathrm{Li}_{7} \mathrm{Ti}_{3} \mathrm{O}_{9} \mathrm{~F}$ is comparable to $\mathrm{Li}_{2} \mathrm{TiO}_{3}$ but higher than the other counterparts. The quality factor is superior to that of $\mathrm{Li}_{2} \mathrm{TiO}_{3}$ but inferior to the $\mathrm{Mg}$-containing compounds. Most importantly, the sintering temperature of $\mathrm{Li}_{7} \mathrm{Ti}_{3} \mathrm{O}_{9} \mathrm{~F}$ is extremely low, which is comparable to that of $\mathrm{Li}_{4} \mathrm{WO}_{5}$. Most of the reported rock salt compounds need high possessing temperatures to densify. Until now, $\mathrm{Li}_{7} \mathrm{Ti}_{3} \mathrm{O}_{9} \mathrm{~F}$ and $\mathrm{Li}_{4} \mathrm{WO}_{5}$ are the exceptional rock salts with a combination of low sintering temperature and outstanding microwave dielectric performances. These findings of merits support their potential utilization in LTCC technology.

\section{Conclusions}

A novel oxyfluoride, $\mathrm{Li}_{7} \mathrm{Ti}_{3} \mathrm{O}_{9} \mathrm{~F}$, is designed and synthesized through solid solution between $\mathrm{Li}_{2} \mathrm{TiO}_{3}$ and $\mathrm{LiF}$. XRD and Rietveld refinement confirm a cubic structure $(\mathrm{Fm}-3 \mathrm{~m})$ with $a=4.1340(1) \AA$. Sintering behavior optimization reveals that $\mathrm{Li}_{7} \mathrm{Ti}_{3} \mathrm{O}_{9} \mathrm{~F}$ could be densified at relatively low sintering temperatures $\leq 950{ }^{\circ} \mathrm{C}$ with a dense microstructure, which is superior to that of the end-number $\mathrm{Li}_{2} \mathrm{TiO}_{3}$. Excellent microwave dielectric properties with $\varepsilon_{\mathrm{r}}=22.5, \mathrm{Q} \times \mathrm{f}=88,200 \mathrm{GHz}$ (with $\mathrm{f}=9.2 \mathrm{GHz}$ ), and $\tau_{\mathrm{f}}=-24.2 \mathrm{ppm} /{ }^{\circ} \mathrm{C}$ were accessible in the sample being sintered at $950{ }^{\circ} \mathrm{C}$. Additionally, $\mathrm{Li}_{7} \mathrm{Ti}_{3} \mathrm{O}_{9} \mathrm{~F}$ has an average $\mathrm{CTE}$ of $11.2 \mathrm{ppm} /{ }^{\circ} \mathrm{C}$ and good chemical compatibility with silver electrodes. The combined excellent dielectric performances, low thermal expansion, and good chemical compatibility make $\mathrm{Li}_{7} \mathrm{Ti}_{3} \mathrm{O}_{9} \mathrm{~F}$ a promising alternative for LTCC applications. The present work may shed light on the design of low-temperature-firing materials through solid solution between oxides and fluorides.

\section{Acknowledgments}

We appreciate Dr. Jibran Khaliq from Northumbria University at Newcastle, UK, for his help in language polishing. This work was supported by the Natural Science Foundation of China (Nos. 21561008, 51502047 and 21761008), the Natural Science Foundation of Guangxi Zhuang Autonomous Region (Nos. 2015GXNSFFA139003, 2016GXNSFBA380134, 2016GXNSFAA380018, 2018GXNSFAA281253, and 2018GXNSFAA138175), and Project of Scientific Research and Technical Exploitation Program of Guilin(20170225).

\section{References}

[1] M.T. Sebastian, R. Ubic, H. Jantunen, Low-loss dielectric ceramic materials and their properties, Int. Mater. Rev. 60 (2015) 392-412.

[2] H. Ohsato, Functional advances of microwave dielectric for next generation, Ceram. Int. 38 (2012) S141S146.

[3] N. Joseph, J. Varghese, T. Siponkoski, M. Teirikangas, M.T. Sebastian, H. Jantunen, Glass-free CuMoO4 ceramic with excellent dielectric and thermal properties for ultralow temperature cofired ceramic applications, ACS Sustain. Chem. Eng. 4 (2016) 5632-5639.

[4] R.J. Cava, Dielectric materials for applications in microwave communications, J. Mater. Chem. 11 (2001) $54-62$.

[5] J. Varghese, T. Siponkoski, M. Teirikangas, M.T. Sebastian, A. Uusimaki, H. Jantunen, Structural, dielectric, and thermal properties of $\mathrm{Pb}$ free molybdate based ultralow temperature glass, ACS Sustain. Chem. Eng. 4 (2016) 3897-3904. 
[6] M.T. Sebastian, H. Wang, H. Jantunen, Low temperature co-fired ceramics with ultra-low sintering temperature: a review, Curr. Opin. Solid State Mater. Sci. 20 (2016) 151-170.

[7] https://doi.org/10.1016/j.ceramint.2019.01.126.

[8] C.C. Xia, D.H. Jiang, G.H. Chen, Microwave dielectric ceramic of LiZnPO4 for LTCC applications, J. Mater. Sci. Mater. Electron. 28 (2017) 12026-12031.

[9] L.L. Yuan, J.J. Bian, Microwave dielectric properties of lithium contained ceramics with rock salt structure, Ferroelectrics 387 (2009) 123-129.

[10] P. Gierszewski, Review of properties of lithium metatitanate, Fusion Eng. Des. 39-40 (1998) 739-743.

[11] H. Kleykamp, Phase equilibria in the Li-Ti-O system and physical properties of Li2TiO3, Fusion Eng. Des. 61-62 (2002) 361-366.

[12] J.J. Bian, Y.F. Dong, Sintering behavior, microstructure and microwave dielectric properties of Li2+xTiO3 $(0 \leq x \leq 0.2)$, Mater. Sci. Eng. B 176 (2011) 147-151.

[13] H.F. Zhou, X.H. Tan, J. Huang, N. Wang, G.C. Fan, X.L. Chen, Phase structure, sintering behavior and adjustable microwave dielectric properties of Mg1-xLi2xTixO1+2x solid solution ceramics, J. Alloy. Comp. 696 (2017) 1255-1259.

[14] H.T. Wu, E.S. Kim, Characterization of low loss microwave dielectric materials Li3Mg2NbO6 based on the chemical bond theory, J. Alloy. Comp. 669 (2016) 134-140.

[15] Y.W. Tseng, J.Y. Chen, Y.C. Kuo, C.L. Huang, Low-loss microwave dielectrics using rock salt oxide Li2MgTiO4, J. Alloy. Comp. 509 (2011) L308-L310.

[16] C.C. Li, H.C. Xiang, C.Z. Yin, Y. Tang, Y.C. Li, L. Fang, Ultra-low loss microwave dielectric ceramic Li2Mg2TiO5 and low-temperature firing via B2O3 addition, J. Electron. Mater. 47 (2018) 6383-6389.

[17] Z.F. Fu, P. Liu, J.L. Ma, X.G. Zhao, H.W. Zhang, Novel series of ultra-low loss microwave dielectric ceramics: Li2Mg3BO6 (B = Ti, Sn, Zr), J. Eur. Ceram. Soc. 36 (2016) 625-629.

[18] J.X. Bi, C.C. Li, Y.H. Zhang, C.F. Xing, C.H. Yang, H.T. Wu, Crystal structure, infrared spectra and microwave dielectric properties of ultra low-loss Li2Mg4TiO7 ceramics, Mater. Lett. 196 (2017) 128-131.

[19] J.X. Bi, Y.J. Niu, H.T. Wu, Li4Mg3Ti2O9: a novel low-loss microwave dielectric ceramic for LTCC, Ceram. Int. 43 (2017) 7522-7530.

[20] H.L. Pan, H.T. Wu, Crystal structure, infrared spectra and microwave dielectric properties of new ultra low-loss Li6Mg7Ti3016 ceramics, Ceram. Int. 43 (2017) 14484-14487.

[21] J. Li, L. Fang, H. Luo, J. Khaliq, Y. Tang, C.C. Li, Li4WO5: a temperature stable lowfiring microwave dielectric ceramic with rock salt structure, J. Eur. Ceram. Soc. 36 (2016) 243-246.

[22] N.V. Tarakina, R.B. Neder, T.A. Denisova, L.G. Maksinova, Y.V. Baklanova, A.P. Tyutyunnik, V.G. Zubkov, Defect crystal structure of new TiO(OH)2 hydroxide and related lithium salt Li2TiO3, Dalton Trans. 39 (2010) 8168-8176.

[23] T. Fehr, E. Schmidbauer, Electrical conductivity of Li2TiO3 ceramics, Solid State lonics 178 (2007) 3541.

[24] J.J. Bian, J.Y. Wu, L. Wang, Structural evolution, sintering behavior and microwave dielectric properties of (1-x)Li3NbO4-xLiF $(0 \leq x \leq 0.9)$, J. Eur. Ceram. Soc. 32 (2012) 1251-1259. 
[25] U. Intatha, S. Eitssayeam, K. Pengpat, K.J.D. MacKenzie, T. Tunkasiri, Dielectric properties of low temperature sintered LiF doped BaFe0.5Nb0.5O3, Matter. Lett. 61 (2007) 196-200.

[26] J.X. Tong, Q.L. Zhang, H. Yang, J.L. Zou, Low-temperature firing and microwave dielectric properties of $\mathrm{Ca}[($ Li0.33Nb0.67)0.9Ti0.1]O3- $\sigma$ ceramics with LiF addition, Matter. Lett. 59 (2005) 3252-3255.

[27] Y. Tang, L. Fang, H.F. Zhou, Q.W. Liu, H. Zhang, Microwave dielectric properties and chemical compatibility with silver electrode of low-fired Li2Cu0.2Mg0.8Ti3O8 ceramics, Ceram. Int. 39 (2013) 85038506.

[28] C.C. Li, H.C. Xiang, M.Y. Xu, Y. Tang, L. Fang, Li2AGeO4 (A = Zn, Mg):Two novel low-permittivity microwave dielectric ceramics with olivine structure, J. Eur. Ceram. Soc. 38 (2018) 1524-1528.

[29] D. Zhou, L.X. Pang, J. Guo, G.Q. Zhang, Y. Wu, H. Wang, X. Yao, Low temperature firing microwave dielectric ceramics (K0.5Ln0.5)MoO4 ( $\mathrm{Ln}=\mathrm{Nd}$ and Sm) with low dielectric loss, J. Eur. Ceram. Soc. 31 (2011) 2749-2752.

[30] C.C. Li, C.Z. Yin, J.Q. Chen, H.C. Xiang, Y. Tang, L. Fang, Crystal structure and dielectric properties of germanate melilites Ba2MGe2O7 ( $M=M g$ and $Z n$ ) with low permittivity, J. Eur. Ceram. Soc. 38 (2018) $5246-5251$.

[31] S. George, M.T. Sebastian, Synthesis and microwave dielectric properties of novel temperature stable high Q, Li2ATi3O8 (A=Mg, Zn) ceramics, J. Am. Ceram. Soc. 93 (2010) 2164-2166.

[32] C.C. Li, H.C. Xiang, M.Y. Xu, J. Khaliq, J.Q. Chen, L. Fang, Low-firing and temperature stable microwave dielectric ceramics Ba2LnV3O11 (Ln = Nd, Sm), J. Am. Ceram. Soc. 101 (2018) 773-781.

[33] C.C. Chiang, S.F. Wang, Y.R. Wang, W.C.J. Wei, Densification and microwave dielectric properties of CaO-B2O3-SiO2 system glass-ceramics, Ceram. Int. 34 (2008) 599-604.

[34] H.C. Xiang, C.C. Li, H. Jantunen, L. Fang, A.E. Hill, Ultralow loss CaMgGeO4 microwave dielectric ceramic and its chemical compatibility with silver electrodes for low-temperature cofired ceramic applications, ACS Sustain. Chem. Eng. 6 (2018) 6458-6466.

[35] Z. Xiong, B. Tang, Z.X. Fang, C.T. Yang, S.R. Zhang, Effects of (Cr0.5Ta0.5)4+ on structure and microwave dielectric properties of $\mathrm{Ca0} .61 \mathrm{Nd} 0.26 \mathrm{TiO} 3$ ceramics, Ceram. Int. 44 (2018) 7771-7779.

[36] J. Khaliq, C.C. Li, K. Chen, B.G. Shi, H.T. Ye, A.M. Grande, H.X. Yan, M.J. Reece, Reduced thermal conductivity by nanoscale intergrowths in perovskite like layered structure La2Ti2O7, J. Appl. Phys. 117 (2015) 075101-075107.

[37] H. Borchert, Y.V. Frolova, V.V. Kaichev, I.P. Prosvirin, G.M. Alikina, Electronic and chemical properties of nanostructured cerium dioxide doped with praseodymium, J. Phys. Chem. B 109 (2005) 5728-5738.

[38] Z.X. Fang, B. Tang, F. Si, S.R. Zhang, Low temperature sintering of high permittivity Ca-Li-Nd-Ti microwave dielectric ceramics with $\mathrm{BaCu}(\mathrm{B} 2 \mathrm{O} 5)$ additives, J. Alloy. Comp. 693 (2017) 843-852.

[39] H.T. Chen, B. Tang, P. Fan, S.X. Duan, M. Wei, Y. Yuan, S.R. Zhang, Microwave dielectric properties of aluminum substituted Ca0.6Nd0.26TiO3 ceramics, J. Ceram. Soc. Jpn. 124 (2016) 903-906.

[40] C.C. Li, X.Y. Wei, L. Fang, H.X. Yan, M.J. Reece, Dielectric relaxation and electrical conductivity in Ca5Nb4TiO17 ceramics, Ceram. Int. 41 (2015) 9923-9930.

[41] I.N. Lin, C.T. Chia, H.L. Liu, Intrinsic dielectric and spectroscopic behavior of perovskite Ba (Ni1/3Nb2/3)O3-Ba(Zn1/3Nb2/3)O3 microwave dielectric ceramics, J. Appl. Phys. 102 (2007) 044112. 
[42] Z. Chen, H. Jia, K. Sharafudeen, W.B. Dai, Y.B. Liu, G.Q. Dong, J.R. Qiu, Up-conversion luminescence from single vanadate through blackbody radiation harvesting broadband near-infrared photons for photovoltaic cells, J. Alloy. Compd. 663 (2016) 204-210.

[43] J. Guo, D. Zhou, L. Wang, H. Wang, T. Shao, Z.M. Qi, X. Yao, Infrared spectra, Raman spectra, microwave dielectric properties and simulation for effective permittivity of temperature stable ceramics AMoO4-TiO2 (A = Ca, Sr), Dalton Trans. 42 (2013) 1483-1491.

\section{Tables and figures}

Table 1 Phonon parameters obtained from the fitting of the infrared reflectivity spectra of $\mathrm{Li}_{7} \mathrm{Ti}_{3} \mathrm{O}_{9} \mathrm{~F}$ ceramic.

\begin{tabular}{|r|l|r|r|r|}
\hline \multicolumn{1}{|l|}{ Mode } & \multicolumn{1}{l|}{$\omega_{\mathrm{oj}}$} & \multicolumn{1}{l|}{$\omega_{\mathrm{pj}}$} & \multicolumn{1}{l|}{$\gamma_{\mathrm{j}}$} & \multicolumn{1}{|c|}{$\Delta \varepsilon_{\mathrm{j}}$} \\
\hline 1 & 133.88 & 318.76 & 134.99 & 5.6700 \\
\hline 2 & 256.63 & 289.24 & 65.67 & 2.3300 \\
\hline 3 & 306.42 & 1168 & 230.99 & 14.500 \\
\hline 4 & 466.17 & 206.47 & 58.214 & 0.1960 \\
\hline 5 & 673.36 & 378.91 & 179.19 & 0.3170 \\
\hline 6 & 802.21 & 173.03 & 55.527 & 0.0465 \\
\hline & $\mathrm{Li}_{7} \mathrm{Ti}_{3} \mathrm{O}_{9} \mathrm{~F}$ & $\varepsilon_{\infty}=1.94$ & $\varepsilon_{0}=23.06$ & \\
\hline
\end{tabular}

Table 2 The sintering temperature (S.T.) and microwave dielectric properties of some rock salts.

\begin{tabular}{|l|c|c|c|c|l|}
\hline Ceramics & S.T. $\left({ }^{\circ} \mathrm{C}\right)$ & $\varepsilon_{r}$ & $\mathrm{Q} \times f(\mathrm{GHz})$ & $\tau_{f}\left(\mathrm{ppm} /{ }^{\circ} \mathrm{C}\right)$ & Reference \\
\hline $\mathrm{Li}_{2} \mathrm{TiO}_{3}$ & 1300 & 22 & 63,500 & 20.3 & {$[9]$} \\
\hline $\mathrm{Li}_{2} \mathrm{ZrO}_{3}$ & 1450 & 15.54 & 37,166 & -26.6 & {$[9]$} \\
\hline $\mathrm{Li}_{3} \mathrm{NbO}_{4}$ & 1150 & 16.4 & 47179 & -45 & {$[9]$} \\
\hline $\mathrm{Li}_{3} \mathrm{Mg}_{2} \mathrm{NbO}_{6}$ & 1225 & 14.94 & 100,965 & -21.96 & {$[14]$} \\
\hline $\mathrm{Li}_{2} \mathrm{MgTiO}_{4}$ & 1360 & 17.25 & 97,300 & -27.2 & {$[15]$} \\
\hline $\mathrm{Li}_{2} \mathrm{Mg}_{2} \mathrm{TiO}_{5}$ & 1320 & 13.4 & 95,000 & -32.5 & {$[16]$} \\
\hline $\mathrm{Li}_{2} \mathrm{Mg}_{3} \mathrm{TiO}_{6}$ & 1280 & 15.2 & 152,000 & -39 & {$[17]$} \\
\hline $\mathrm{Li}_{2} \mathrm{Mg}_{4} \mathrm{TiO}_{7}$ & 1600 & 13.43 & 233,600 & -7.24 & {$[18]$} \\
\hline $\mathrm{Li}_{4} \mathrm{Mg}_{3} \mathrm{Ti}_{2} \mathrm{O}_{9}$ & 1450 & 15.97 & 135,800 & -7.06 & {$[19]$} \\
\hline $\mathrm{Li}_{6} \mathrm{Mg}_{7} \mathrm{Ti}_{3} \mathrm{O}_{16}$ & 1550 & 15.27 & 209,400 & -11.32 & {$[20]$} \\
\hline $\mathrm{Li}_{4} \mathrm{WO}_{5}$ & 890 & 8.6 & 23,100 & -2.6 & {$[21]$} \\
\hline $\mathrm{Li}_{7} \mathrm{Ti}_{3} \mathrm{O}_{9} \mathrm{~F}$ & 950 & 22.5 & 88,200 & -24.2 & this work \\
\hline
\end{tabular}


(a)

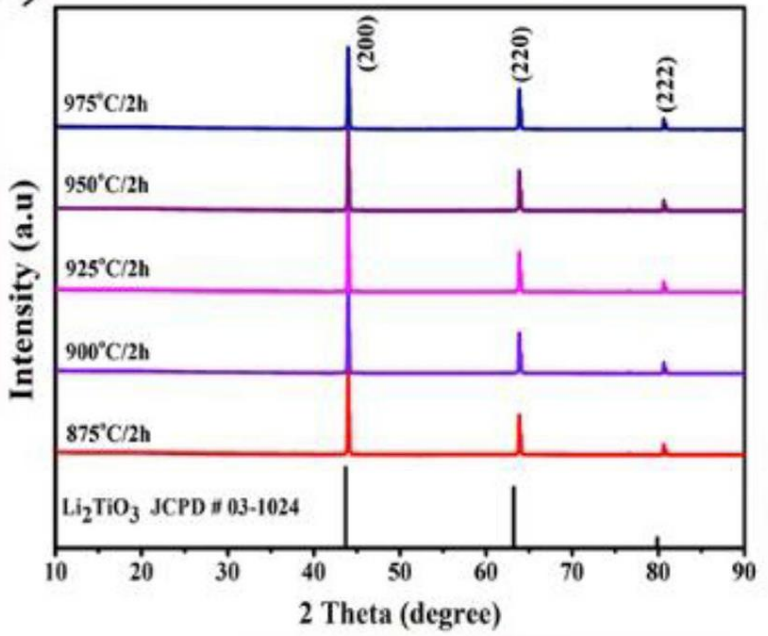

(c)

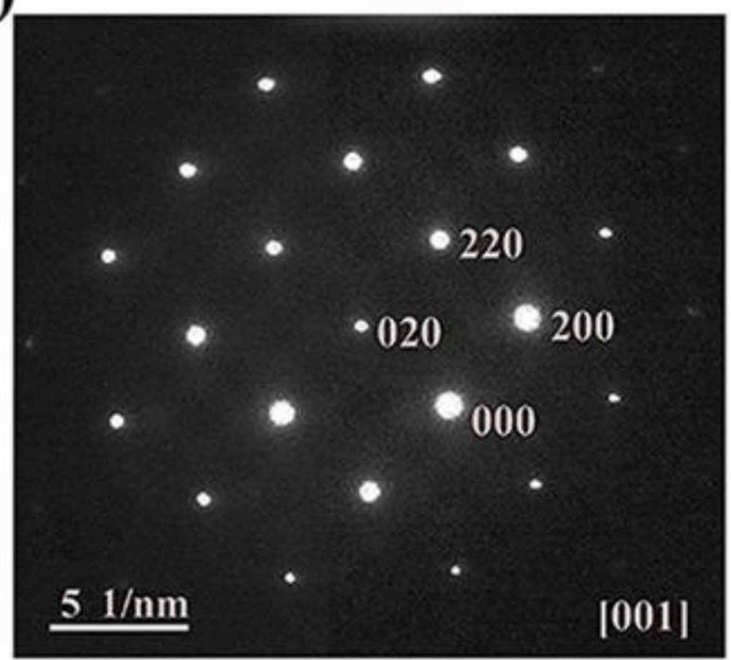

(b)

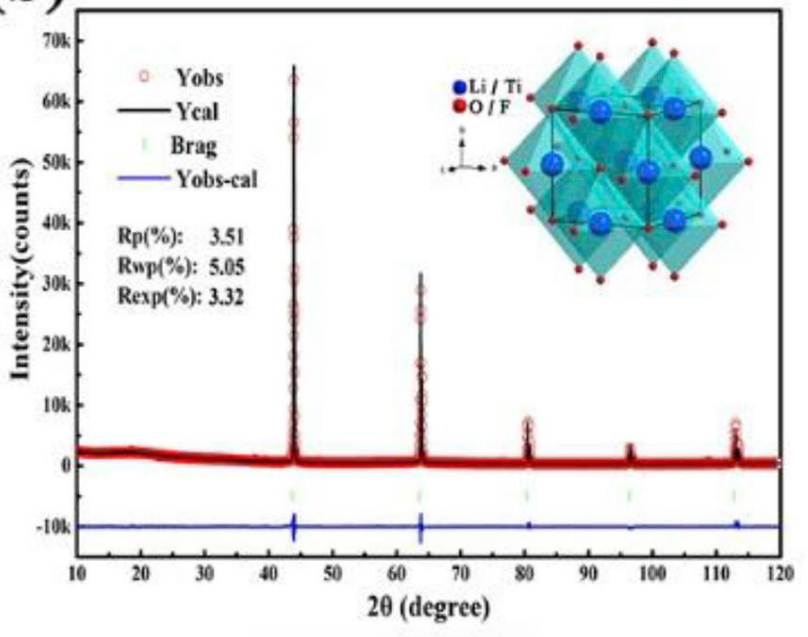

(d)

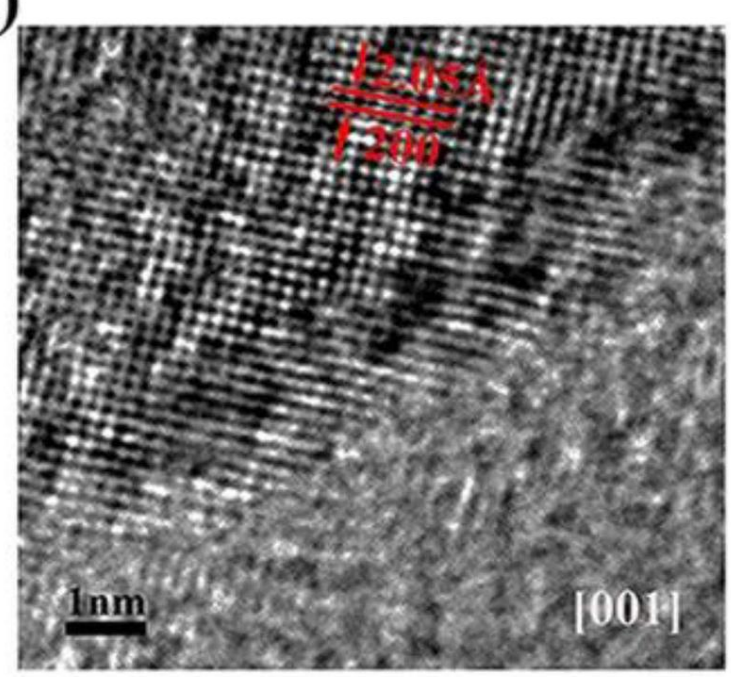

Fig. 1. (a) XRD patterns of $\mathrm{Li}_{7} \mathrm{Ti}_{3} \mathrm{O}_{9} \mathrm{~F}$ ceramic sintered at $875-975^{\circ} \mathrm{C}$ for $2 \mathrm{~h}$. (b) Rietveld refinement of sample sintered at $950^{\circ} \mathrm{C}$ and schematic of the crystal structure for $\mathrm{Li}_{7} \mathrm{Ti}_{3} \mathrm{O}_{9} \mathrm{~F}$. (c) selected area electron diffraction (SAED) pattern of $\mathrm{Li}_{7} \mathrm{Ti}_{3} \mathrm{O}_{9} \mathrm{~F}$ sample sintered at $950{ }^{\circ} \mathrm{C}$. (d) high-resolution transmission electron microscopy (HRTEM) images of $\mathrm{Li}_{7} \mathrm{Ti}_{3} \mathrm{O}_{9} \mathrm{~F}$ ceramic recorded along the [001] zone axis. 


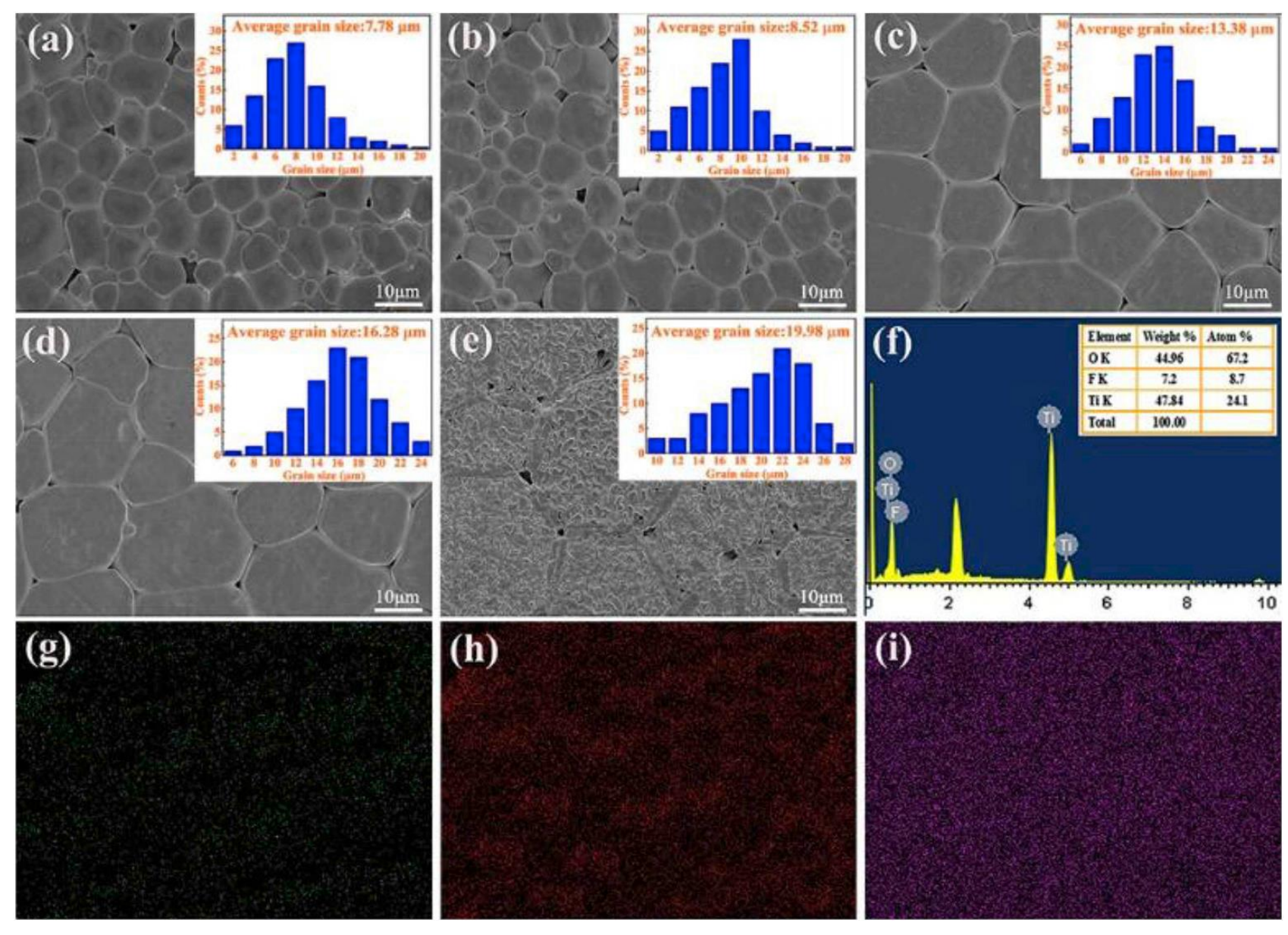

Fig. 2. FE-SEM images of the surfaces of the sintered ceramic at: (a) $875^{\circ} \mathrm{C}$, (b) $900{ }^{\circ} \mathrm{C}$, (c) $925^{\circ} \mathrm{C}$, (d) $950{ }^{\circ} \mathrm{C}$, (e) $975^{\circ} \mathrm{C}$ for $\mathrm{Li}_{7} \mathrm{Ti}_{3} \mathrm{O}_{9} \mathrm{~F}$ and corresponding EDS analysis surface scanning of (f) EDS spectrum (g) $\mathrm{F}$ element, (h) $\mathrm{O}$ element, (i) Ti element.

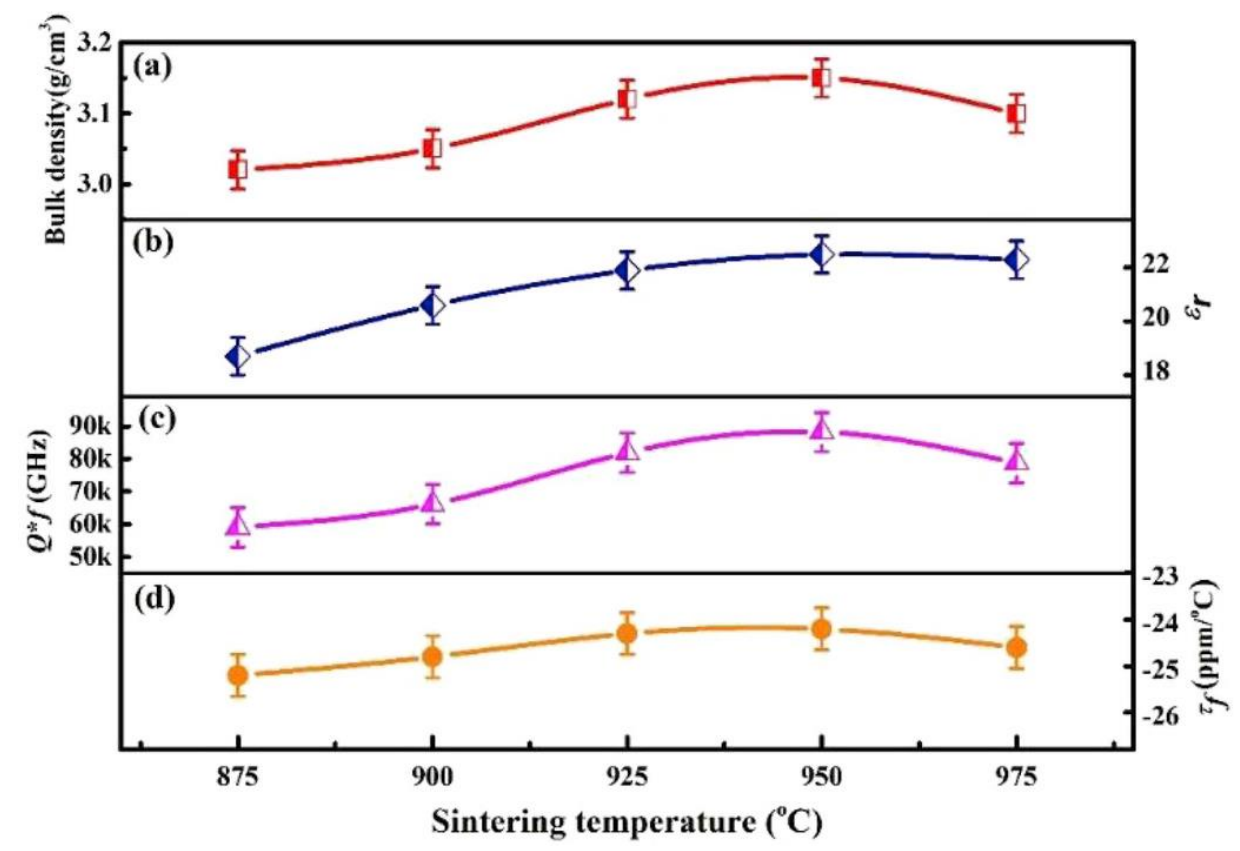

Fig. 3. The bulk density and microwave dielectric properties $\left(\varepsilon_{r}, \mathrm{Q} \times f\right.$, and $\left.\tau_{f}\right)$ of $\mathrm{Li}_{7} \mathrm{Ti}_{3} \mathrm{O}_{9} \mathrm{~F}$ ceramic sintered at different temperatures. 

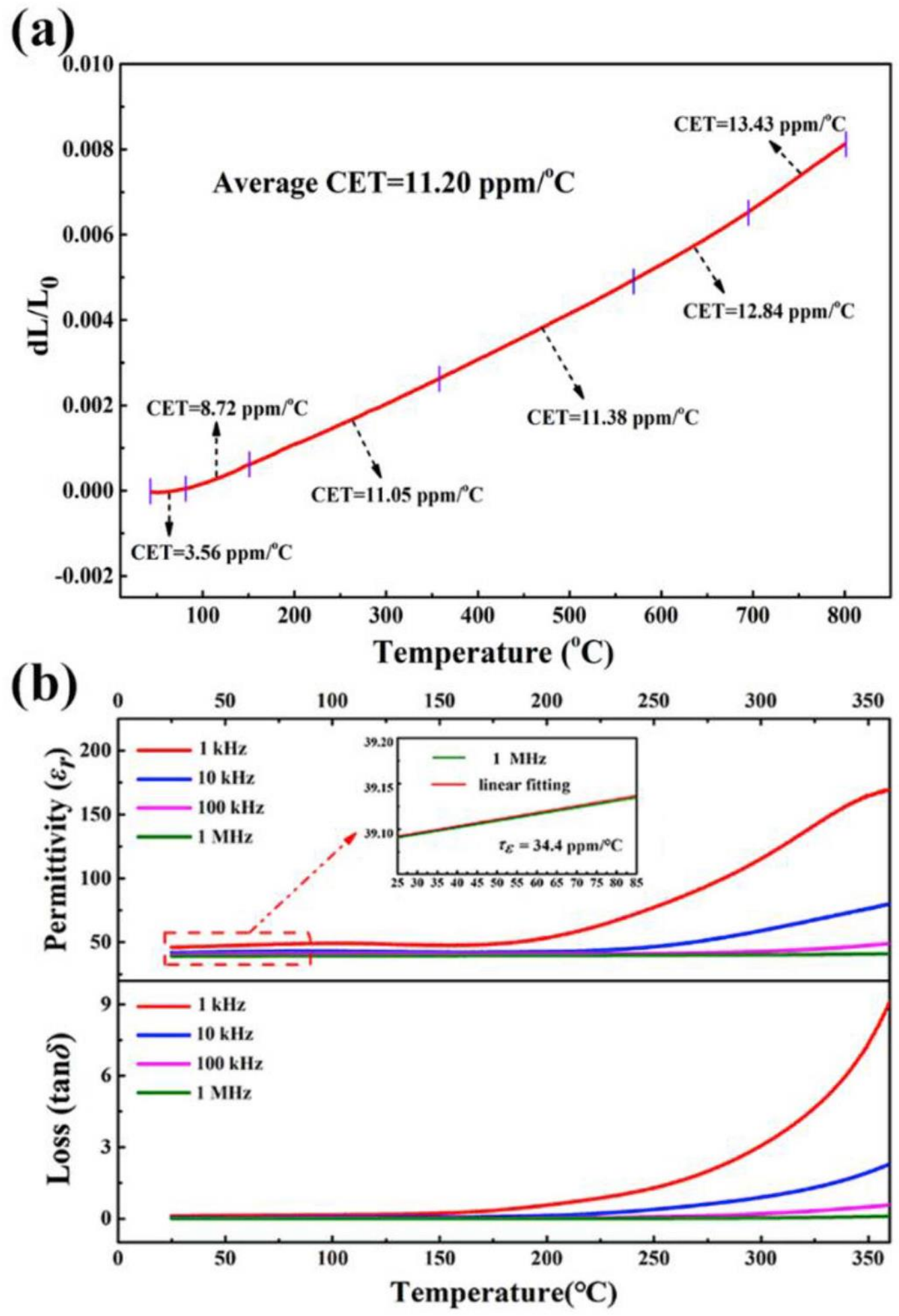

Fig. 4. (a) Thermal expansion curve in the temperature range $25-800{ }^{\circ} \mathrm{C}$ of $\mathrm{Li}_{7} \mathrm{Ti}_{3} \mathrm{O}_{9} \mathrm{~F}$ sintered at $950{ }^{\circ} \mathrm{C}$. (b) Dependence of relative permittivity $\left(\varepsilon_{\mathrm{r}}\right)$ on temperature and loss tangent $(\tan \delta)$ at four different frequencies $(1,10$, and $100 \mathrm{kHz}$ and $1 \mathrm{MHz})$. 

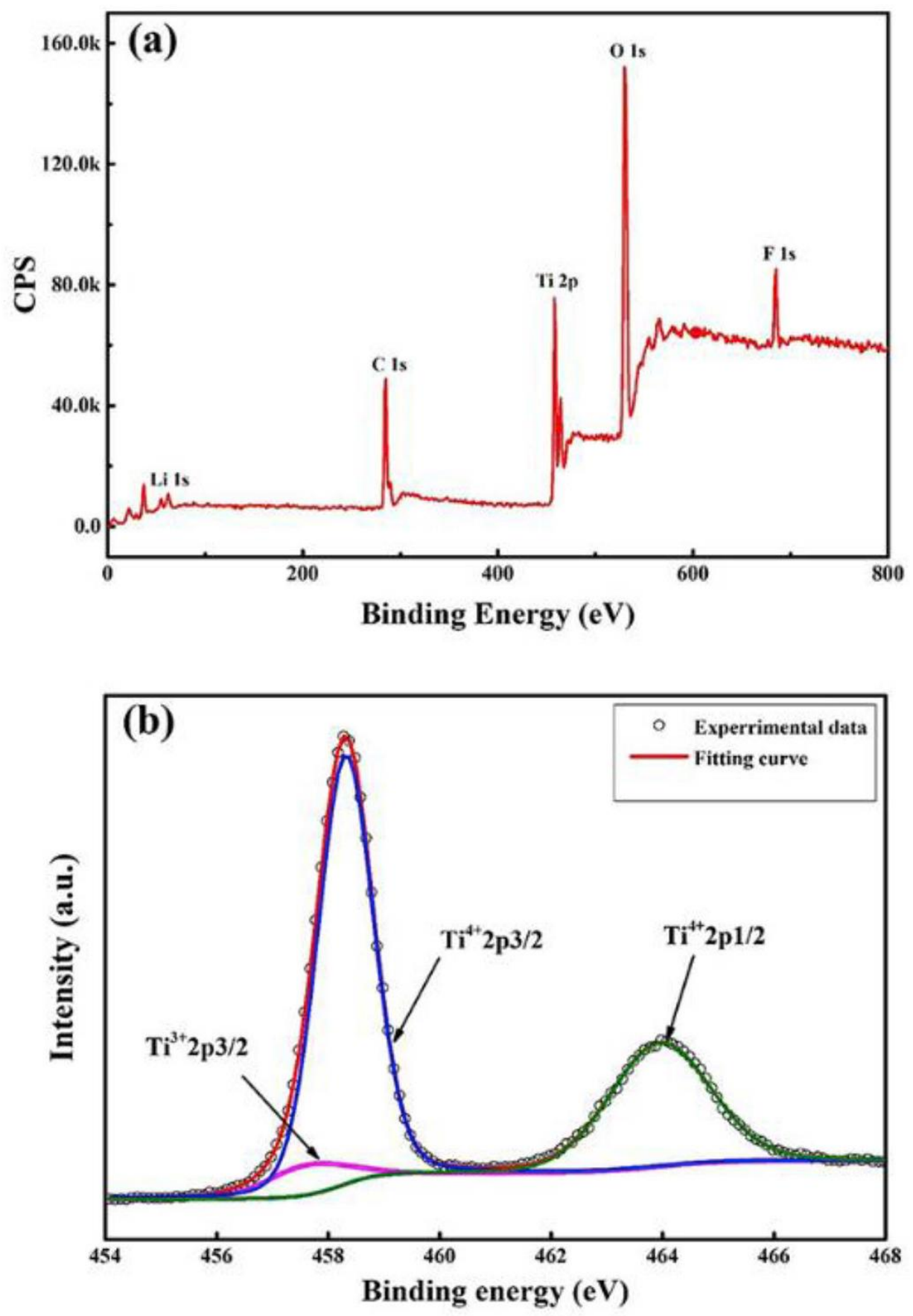

Fig. 5. (a) XPS survey scan of $\mathrm{Li}_{7} \mathrm{Ti}_{3} \mathrm{O}_{9} \mathrm{~F}$ sample sintered at $950{ }^{\circ} \mathrm{C}$ for $2 \mathrm{~h}$. (b) High-resolution XPS spectra for Ti-2p photoelectron peaks. 


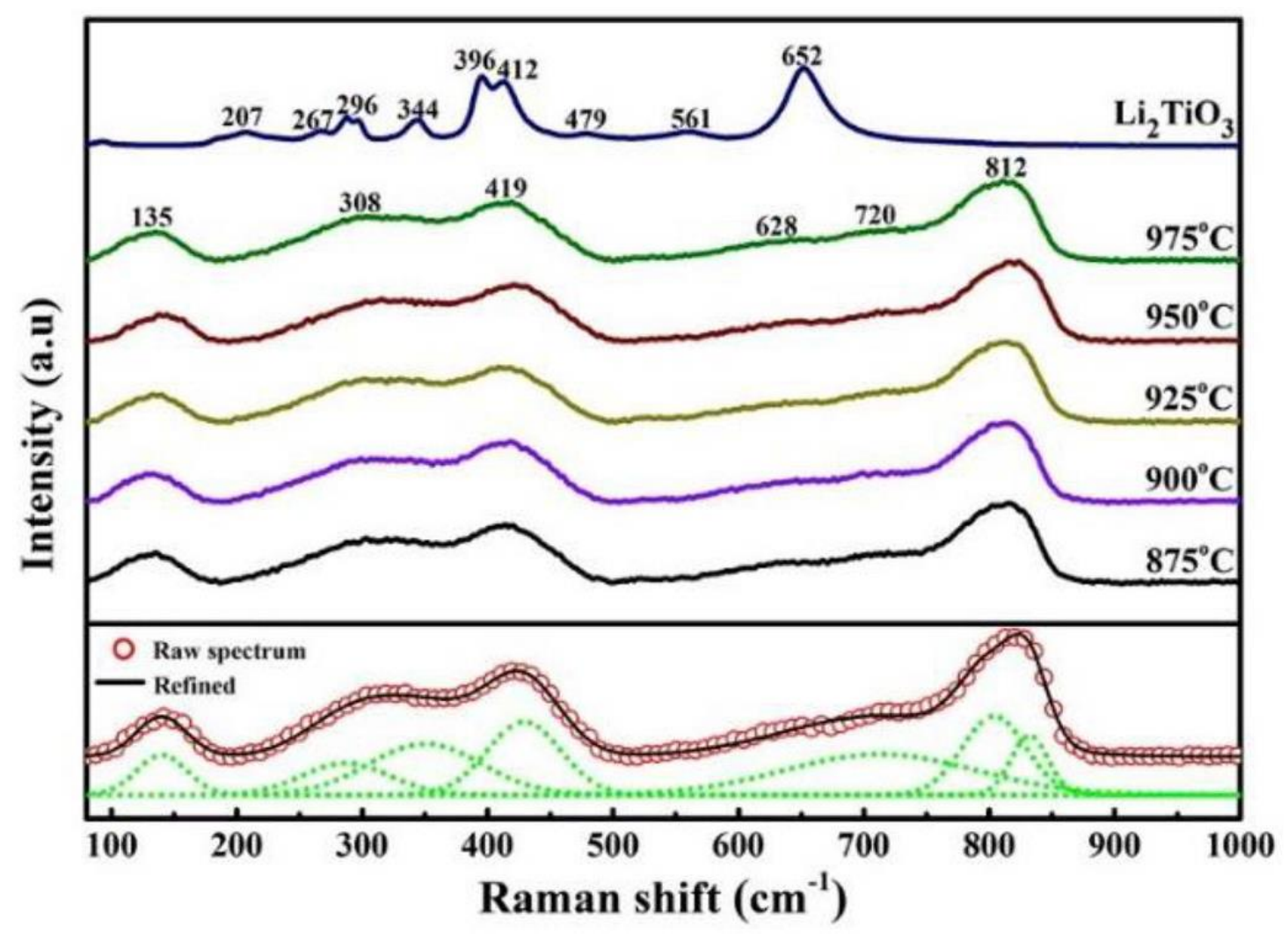

Fig. 6. Raman spectra of pure $\mathrm{Li}_{2} \mathrm{TiO}_{3}$ sample sintered at $1300{ }^{\circ} \mathrm{C}$ and $\mathrm{Li}_{7} \mathrm{Ti}_{3} \mathrm{O}_{9} \mathrm{~F}$ ceramic sintered at $875-975$ ${ }^{\circ} \mathrm{C}$ in the range of $80-1000 \mathrm{~cm}^{-1}$.

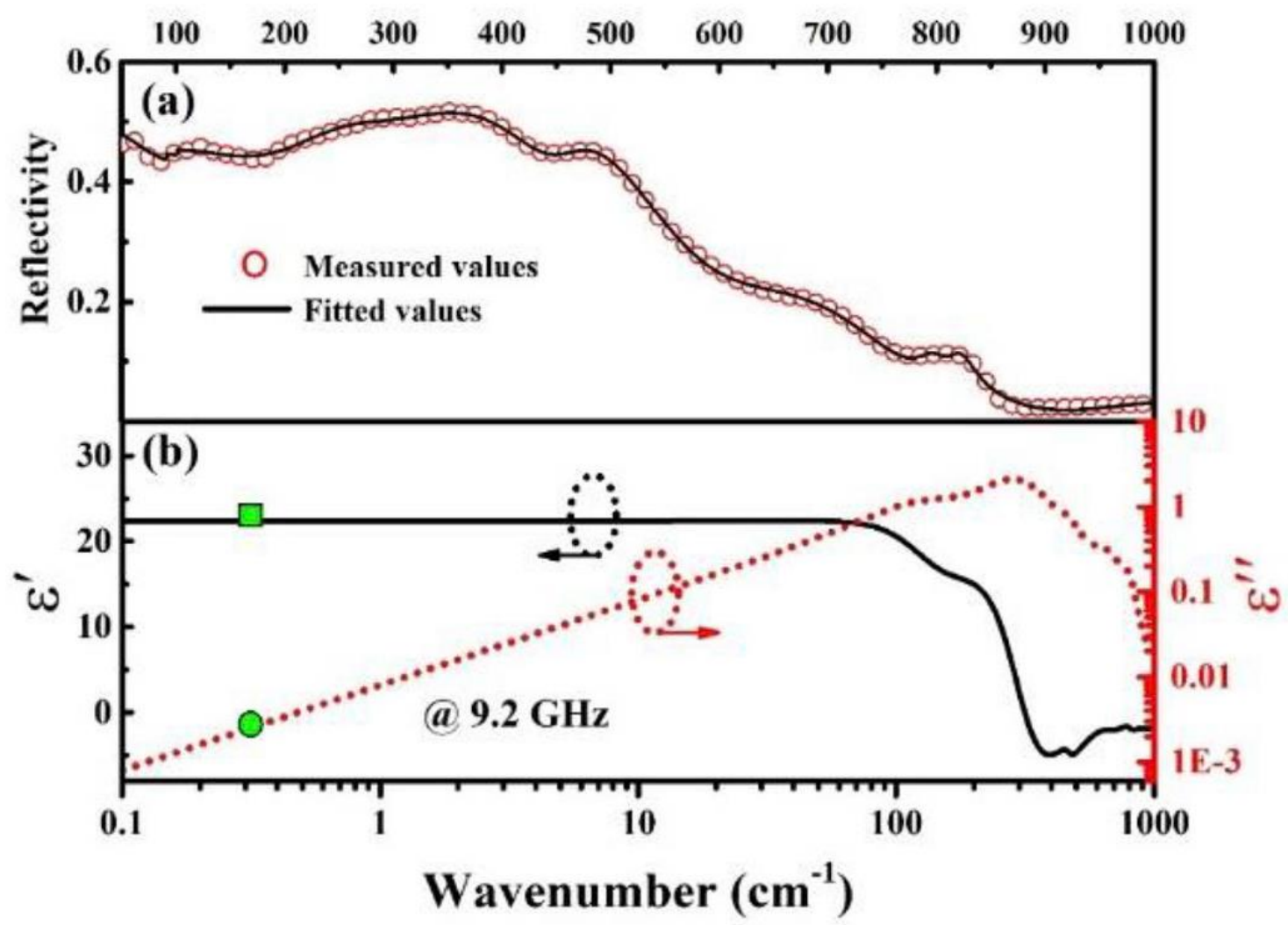

Fig. 7. (a) The measured and fitted IR reflectivity spectra of the $\mathrm{Li}_{7} \mathrm{Ti}_{3} \mathrm{O}_{9} \mathrm{~F}$ ceramic in the range $50-1000 \mathrm{~cm}^{-1}$. (b) The measured and fitted real and imaginary parts of permittivity. 


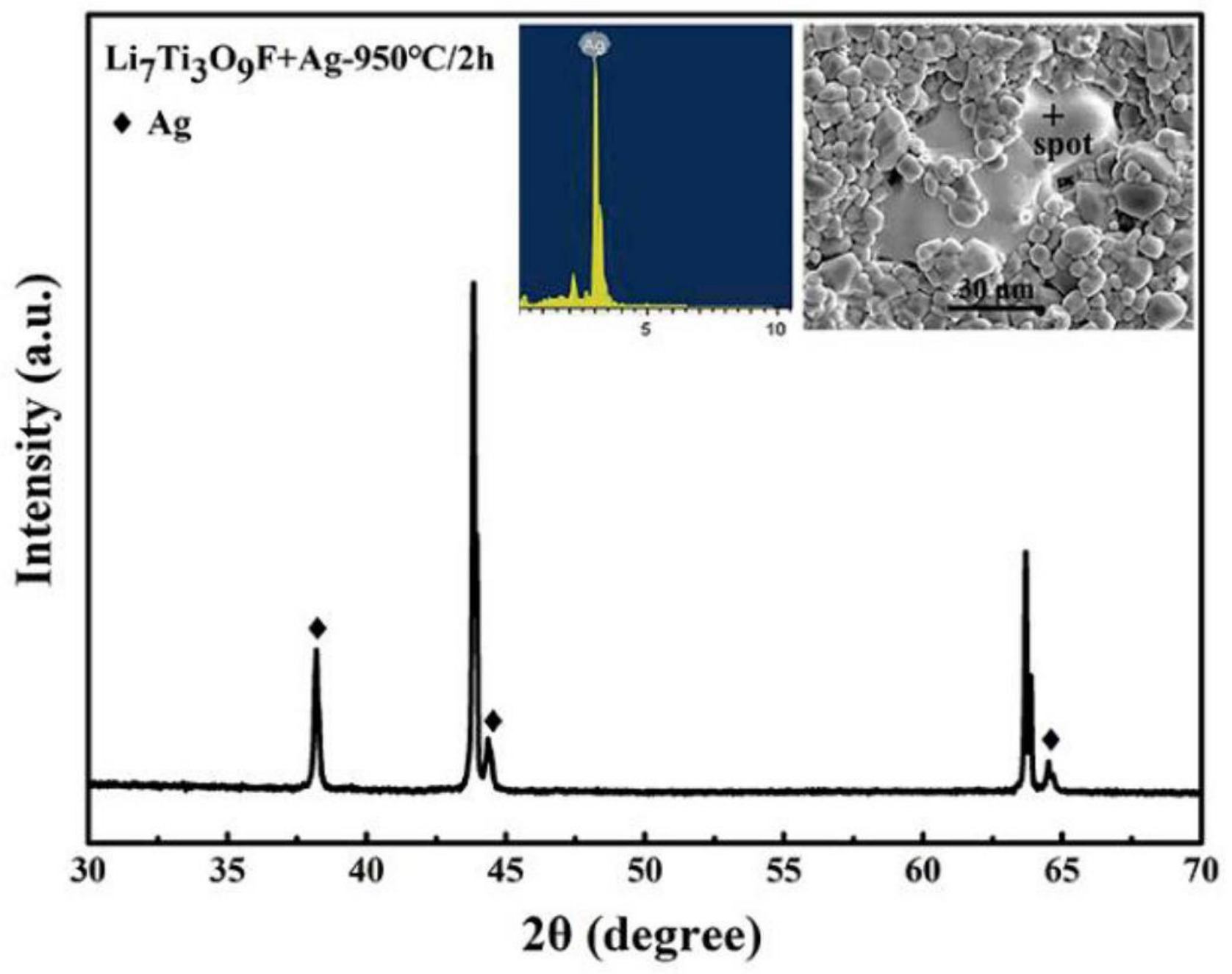

Fig. 8. XRD and BSEM analysis of the cofired $\mathrm{Li}_{7} \mathrm{Ti}_{3} \mathrm{O}_{9} \mathrm{~F}$ ceramic cofired with $20 \mathrm{wt} \% \mathrm{Ag}$ at $950{ }^{\circ} \mathrm{C}$ for $2 \mathrm{~h}$. 